\title{
Public-private partnerships for multifunctional sustainable land use in peri-urban areas to mitigate the adverse effects of climate change
}

\author{
Anna Ternell ${ }^{1}$, Anders M. Nilsson ${ }^{2}$, Björn Ohlén ${ }^{2}$, Daniel Stenholm³ ${ }^{3}$ Dag Bergsjö ${ }^{3}$ \\ ${ }^{1}$ PE Teknik \& Arkitektur; ${ }^{2}$ Region Västra Götaland/Västarvet; ${ }^{3}$ Chalmer's University of Technology \\ e-mail: anna.ternell@pe.se
}

\begin{abstract}
Climate change increases the risk of damage caused by storms, insects and fungi in agriculture and forestry. Multifunctional sustainable land use, including a more diversified agriculture and forestry sector in terms of biodiversity, is one way to create resilience and meet these climate risks. For example, a forest with trees of different ages and of several species is more resistant to these risks. Multifunctional refers to how the same land can provide food and wood products, but also job creation, recreation and be a provider of ecosystem services such as pollination, erosion protection and biodiversity. Research shows that there is a large acceptance for a more varied forest sector and diversified agriculture. In recent years, urban farming has received widespread understanding on its many advantages, including a sense of belonging and meaning, other than food production. In this article the authors try to assess a scenario when these initiatives become commercial and when the urban farming trend meets traditional forms of agriculture and forestry. Furthermore, the large potential of developing public-private partnerships for multifunctional sustainable land use in peri-urban areas in the Swedish City of Gothenburg and its surrounding area is analysed, based on experiences from ongoing initiatives. Developed within the framework of Climate KIC Accelerator Project, a business model is presented allowing for a long-term sustainability of initiatives.
\end{abstract}

Keywords - climate change, sustainability, multifunctional land use, ecosystem services, biodiversity, multifunctional agriculture

Accepted: December 31, 2020

\section{INTRODUCTION}

In recent years, urban farming has received widespread understanding on the many advantages, including a sense of belonging and meaning, other than food production. There is a large acceptance for a more varied forest sector and diversified agriculture since forests provide several valuable ecosystem services (Eriksson et. al 2017). In this article, we ask what happens when these initiatives become commercial and when the urban farming trend meets traditional forms of agriculture and forestry. The area where urban farming and traditional agriculture and forestry meet is ideal in the peri- urban zones, i. e. the suburbs and outskirts of our cities (Piorr et al. 2011). Here, there is more space than in the urban areas and it is closer to the market, infrastructure and work force compared to rural areas. With the clear benefits mentioned above, the vast areas of underutilised land and the willingness to develop ecosystem services, the potentials are great for new innovative initiatives in peri-urban areas. Only a few projects focus on the economic sustainability of initiatives (EEA, 2006). Therefore, this Climate $\mathrm{KIC}^{1}$ project emphasises a business model allowing for a long-term sustainability of initiatives (Stigson et al. 2009). Gothenburg is an interesting case because several projects related to

1 Climate-KIC is Europe's largest public-private innovation partnership focused on climate innovation to mitigate and adapt to climate change. 
multifunctional, sustainable peri-urban land use and green business models are ongoing in all sectors of the society. In addition, the City of Gothenburg and Region Västra Götaland (onwards referred to as the Region) have an interest and commitment to engage in these initiatives allowing for a multi-stakeholder process.

The first aspect, multifunctional land use is a land use system that integrates forestry, agriculture and agroforestry with fruit-bearing trees and shrubs, and animal husbandry (Olsson $\&$ Olsson, 2016). This type of land use offers one way to create resilience and meet climate risks, such as increased risk of damage caused by, for example, storms, insects, and fungi. It also refers to how the land use provides value in terms of, for example, recreation and job opportunities. In the City of Gothenburg, the forest policy states that clear-cuts shall not be practised, instead selective forestry is prioritised referring to a selective harvest of trees with less disturbance to the ecosystem (Watson et al. 2000). We see the need of land use policies supporting the practice of multifunctional land use such as for example agroforestry and selective forestry. The development of sustainable land use has, by policymakers, civil servants, and practitioners, typically focused on land use from isolated perspectives. Less attention has been given to a more systematic view on sustainable practices in the forest sector and the agriculture-forest intersection. Multifunctional sustainable land use is closely related to agroforestry referring to "land-use systems in which trees are grown in combination with agriculture on the same land" (European Commission, 2016). Agroforestry is a term originally used for tropical land use and is now becoming a more widely used term also in temperate areas.

Currently, agroforestry products are only contributing to the local economy at a small scale. At the same time, demand for locally produced organic food increases rapidly in the City's institutions, households, shops, and restaurants (Ekoweb, 2016). The demand for wood products and bioenergy has also increased, but the local production is still insignificant, since most of the raw materials leave Gothenburg, instead of being further processed locally. Ultimately, this is an issue of food safety and future resilience of the city. While seen as a strategy, the City and the Region currently can benefit from models that scale up the business opportunities among the local entrepreneurs. Since climate change increases the risk of damage caused by storm, insects and fungi in agriculture and forestry, multifunctional sustainable land use, including a more diversified agriculture and forestry sector in terms of biodiversity, is one way to create resilience and meet these climate risks. For example, a forest with trees of different ages and of several species is more resistant to these risks. Multifunctional refers to how the same land can provide food and wood products, but also job creation, recreation and be a provider of ecosystem services such as pollination, erosion protection and biodiversity. Research shows that there is a

${ }^{2} \mathrm{COWI} \mathrm{A} / \mathrm{S}$ is an international consulting group, specialising in engineering, environmental science and economics. The name large acceptance for a more varied forest sector and diversified agriculture (Lindahl et al. 2015). Some farmers are focusing on intensive production of high-value-added products, such as special herbs and vegetables for high-end customers as well as basic food stuffs as a way of diversifying agriculture (Hunter et.al 2017). Such activities can become an important income source for the farmer and optimising the proximity to customers with these needs and should be acknowledged in policymaking.

The second aspect, peri-urban land use, is defined as the area between the urban and rural areas (FAO, 1997, 2017). The peri-urban areas access larger areas of agricultural and forestland compared to urban areas and the peri-urban area can benefit from available work force, infrastructure, and urban services, which is not as evident in rural areas. A more sustainable development requires more policy attention at the regional level and at the urban-rural interface. Moreover, the potentials for urban and peri-urban land use are both due to the availability of non-built public land and the demand from citizens of the use the land to produce for example food and recreational services. Peri-urban agriculture and forestry involve complex interactions of social, economic and environmental aspects in locations that are undergoing rapid change and often with inadequate financial means and political support to respond (FAO, 2017). Still, there is a large potential to develop the land in close vicinity to the city as well as in the suburbs. Cost savings can be achieved because of, for example, the proximity to the market and less need for transportation and preservation of fresh products.

The transition towards more sustainable forestry (Alfaro et al, 2010) management, such as agroforestry, would thus benefit from a business model that provides higher value for the harvested trees and crops through identifying potential products for the local market and matching landowners with local businesses as well as rehabilitating peri-urban land and to create business and create job opportunities. It will further look at the local market, new ways for public procurement and other value-added benefits such as the attractiveness of peri-urban areas and contribution to climate mitigation and adaptation.

The objective of the project is to develop and validate a business model for multifunctional sustainable land use in order to stimulate the availability of underutilised peri-urban land in Gothenburg in a designated area in Region Västra Götaland called LAB190. This aims to enable business opportunities and value for local entrepreneurs and landowners, thus increasing work opportunities, and contributing to social sustainability. This will further strengthen the ecosystem services, biodiversity and climate adaptation as described below. The project (completed in November 2017) was a collaboration between COWI, ${ }^{2}$

COWI comes from the initials of Christen Ostenfeld. and Wriborg W. Jønson, the senior partners of the company. 
Chalmer's University of Technology and Region Västra Götaland.

The third aspect, multi-stakeholder processes, is central for encouraging the development of multifunctional sustainable land use in peri-urban areas. One example in the City of Gothenburg and the surrounding area, is through publicprivate partnerships, which for example, are supported by the regional platform for sustainable development, LAB190, manged by the Region Västra Götaland. This platform includes four municipalities and has a great potential for fostering multifunctional sustainable land use as it is well integrated in the municipalities, at the level of civil servants and the politicians. One way is to continue to develop the Business Improvement District for sustainable food production, where cooperation between different actors of society is formalised, as of December 2017 being established.

\section{GOTHENBURG AND THE SURROUNDING REGION}

\section{The City of Gothenburg}

In the 1940s, Gothenburg saw a rapid population growth and the first satellite settlement was built outside the City centre. In the 1950s and 1960s, Gothenburg continued its expansion and established several satellite settlements in the suburban areas. In 1967, the City of Gothenburg incorporated these areas and had its biggest increase of urban area throughout time. The City owns today about $60 \%$ of the land in Gothenburg and about $70 \%$ of the urban areas consists of green areas. Plans were to continue to grow along an era of industrial development and population growth and the City purchased and secured land with the purpose of future expansion in the peri-urban areas. Much of this land is former agriculture and forestland. The development did not happen as anticipated, mainly due to the shipbuilding and oil crises (EEA, 2006). Significant natural resources around Gothenburg therefore remained uncultivated and unplanned, as the biggest landowner, the City of Gothenburg, had no resources to maintain and develop the land.

Large parts of these natural areas have become bush wood. The traditional agricultural businesses in rural areas have declined giving more room for grazing animals and horse keeping. Today, about $10 \%$ of the land in Gothenburg is agricultural land (5000 ha), i.e. arable land and pastures (Melander, 2013). According to the statistics, arable land has decreased with about $20 \%$ during the last decade (Statens jordbruksverk, 2017; Melander, 2013). The development of sustainable land use has, by policymakers and practitioners in Gothenburg typically focused on sustainable agriculture from isolated perspectives. Less attention has been given to a more systematic view on sustainable practices in the forest sector and the agriculture-forest intersection. New and sustainable ecosystem-based management and cultivation of city close natural land areas hold a potential for improved environmental management, such as to enhance the supply of ecosystem services while meeting the pluralistic needs of a growing population. This is reflected in the City's goals and strategies.
As for forestland, the City has politically established the goal to maintain and develop the forests, to achieve diversified and environmentally friendly forest management, identify the forests contribution to ecosystem services, and to improve biodiversity. As such, the City has decided to make land available for projects and research as well as other cooperation with organisations. The City further has decided to forbid clear-cutting and is instead introducing nature-based forestry according to the Lubeck model, Close to Nature Forestry model (CTNF-model) etc. In Swedish the term "hyggesfritt skogsbruk" is used by the City. The term is in this report translated to no-clear-cut-forestry. We will also refer to "selective forestry" meaning similar principles. As for agriculture, Gothenburg, as well as other Swedish cities, have changed the regulations and do now allow private persons to lease land from the City for commercial purposes (Rasmusson et al, 2016). Previously, private persons could rent land in the form of allotments for example. However, this rental form only allowed food production for personal use. The peri-urban areas constitute an important resource with the potential for managing larger pieces of land compared to urban centres.

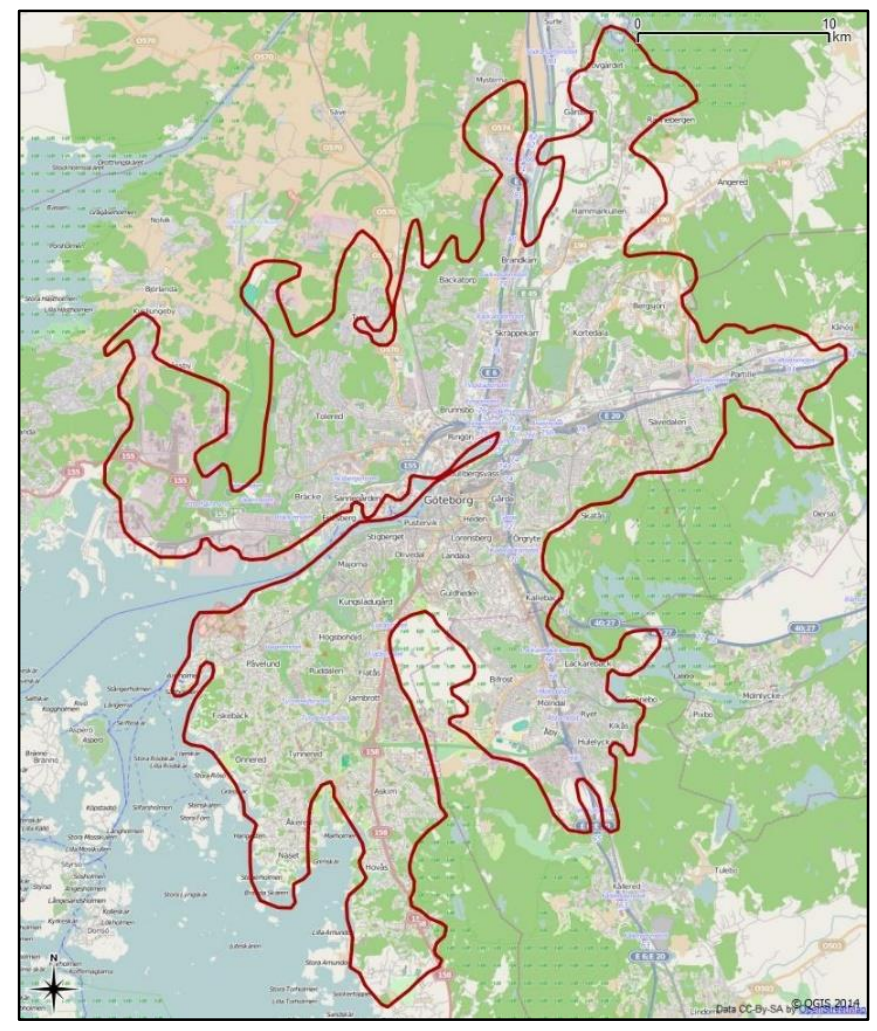

Figure 1. The municipality of Gothenburg after the expansion in 1974. Source: City of Gothenburg (2017)

The surrounding region: lab190 - proposed test area for scaling up the business model

It is important to develop new governance- and business models connected to the use of the landscape to build a more sustainable development (Nilsson et al. 2012). The Region Västra Götaland has a regional development strategy with one of the main goals to strengthen rural-urban interaction and develop new models for innovation-driven development 
in rural areas. To achieve this goal, a change in mind-set of the policymakers, stakeholders and end-users is required as well as the image of rural areas. One way to boost the image of the rural areas is concerns for the development and management of the landscape (Council of Europe, 2000).

Our proposed business model takes its basis in this area and links into the ongoing work on sustainable development. Below follows a presentation of the work and area of

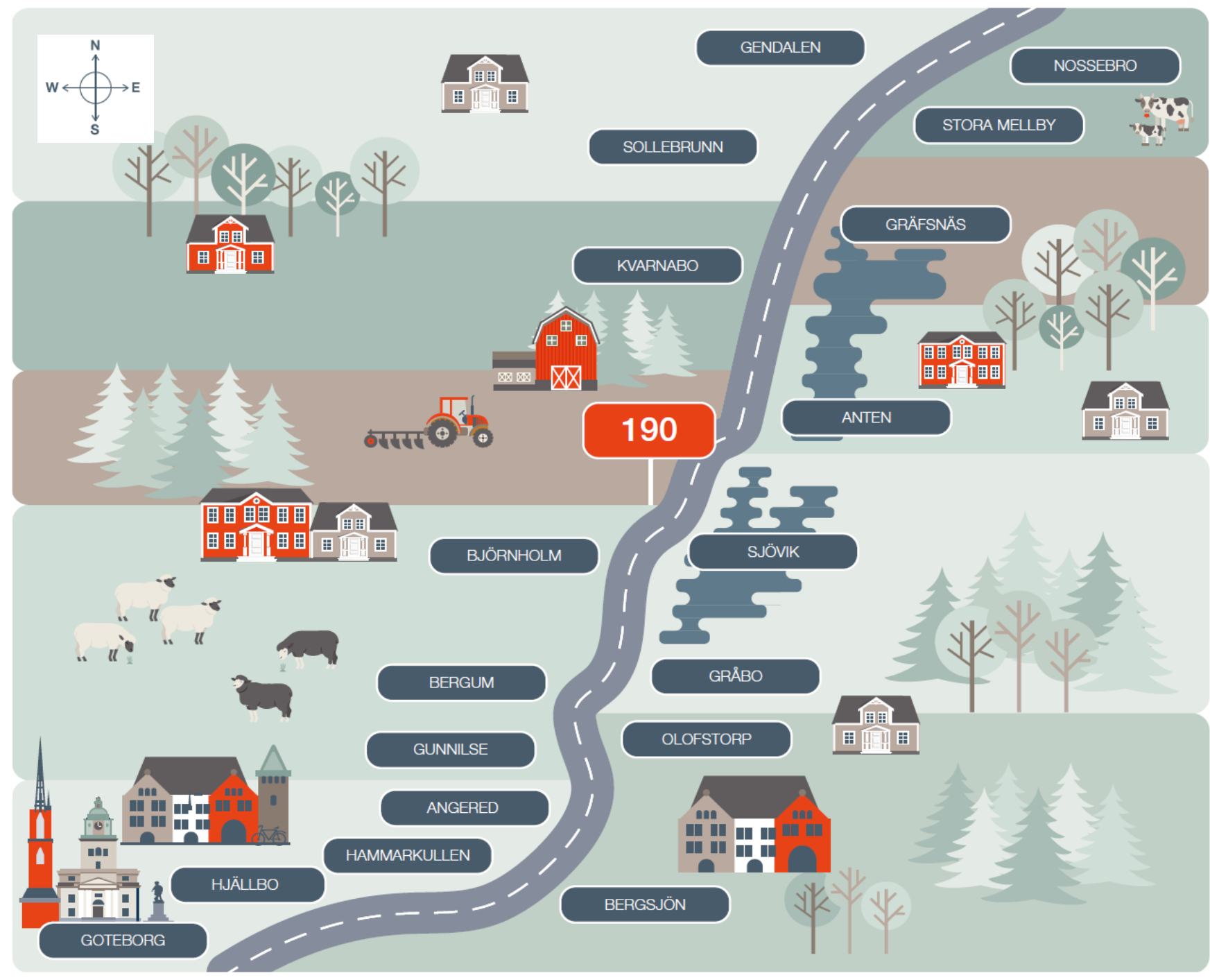

Figure 2. LAB190 area illustrating the road 190 and the different villages and towns in the area. This section of the road starts in the south by the City of Gothenburg and ends approximately $70 \mathrm{~km}$ further north. Source: Authors' design

The area of the city is 721.64 square kilometres, of which 271.41 square kilometres are water; $70 \%$ of the urban area consists of green areas (City of Gothenburg, 2017) to emphasise the rural cultural heritage values. In order to link the urban and rural areas, the Region has designated an area for this purpose, called LAB190. This area has become a model area for sustainable development and emphasises the importance of that business development, biodiversity and social cohesion go hand in hand. Linking issues that concern both urban and rural inclusive and sustainable development is of greatest importance to, e. g. breaking segregation. The process is also a way to try new ways of addressing challenges such as climate change and loss of biodiversity. In this way, the Region plays an important role in the common
LAB190. The LAB190 works within the development and management of the landscape and tries out new methods to mitigate and cope with climate change and loss of biodiversity. It was initiated in 2013 by the Regional Heritage Agency (Västarvet). It is the largest agricultural area in the Gothenburg region and has unique opportunities for developing green and innovative environment industries and sustainable tourism. The concept is a long-term collaboration platform along road 190 from the City of Gothenburg and about $70 \mathrm{~km}$ into the countryside (Figure 2). LAB190 aims at creating a model for inclusive sustainable regional development using nature and cultural heritage as a driving force. The model has broad abutment in the area and partners of LAB190 are the city of Gothenburg, the Municipalities of Lerum, Alingsås, Essunga, the association of local authorities 


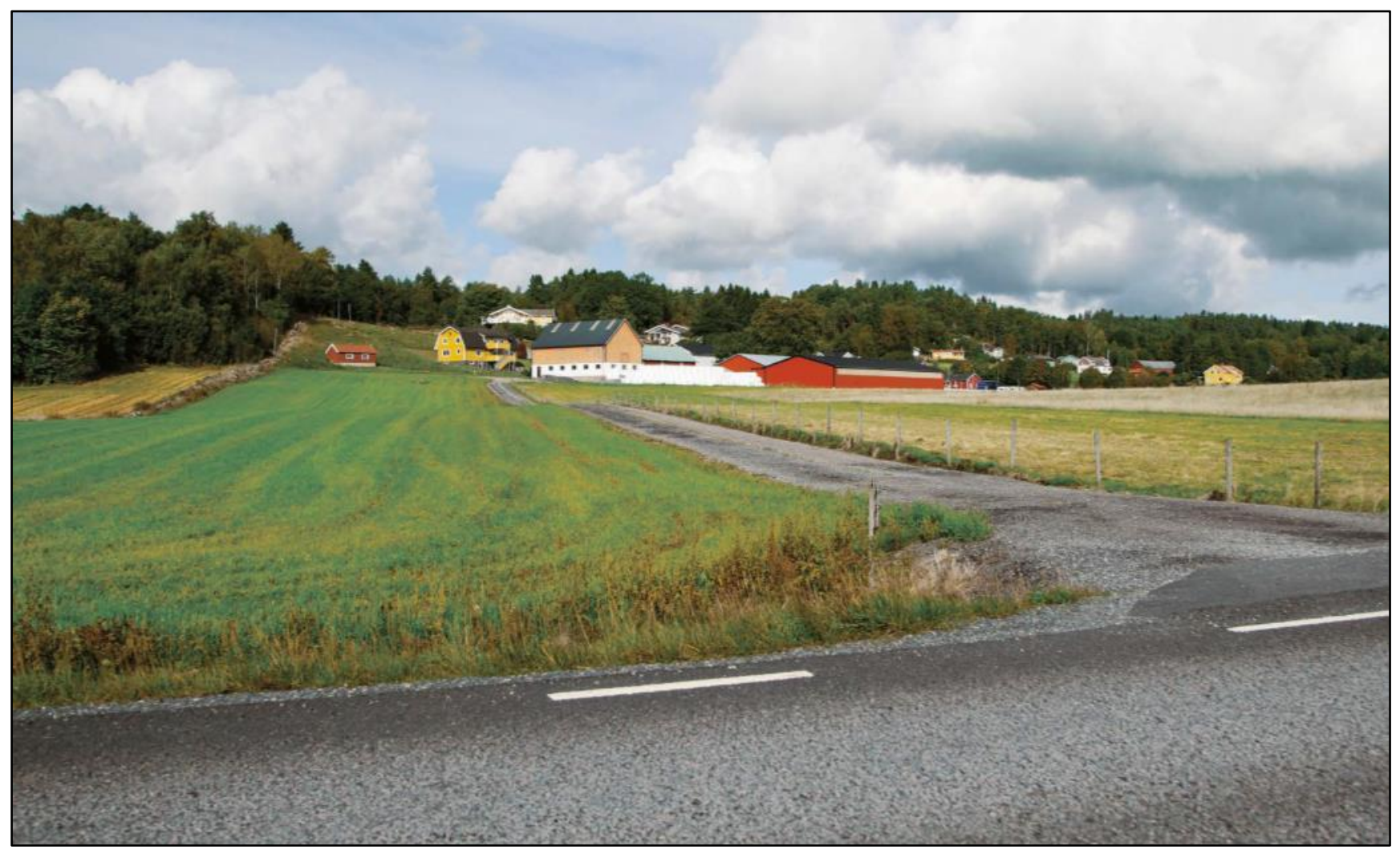

Figure 3. A photo of a typical landscape in the Lab190 area with agricultural and forestry land. Photo: Anders M. Nilsson.

of Gothenburg region, the Regional Heritage Agency (Västarvet), Business Region Gothenburg and the county administrative board in Region Västra Götaland. LAB190 is based on the objectives of the European Landscape Convention. The landscape is central and is linked regardless of territorial or subject boundaries. Another important purpose is the ability of residents to influence and contribute to the landscape development. A broad collaboration concerning the area's development strengthens the interaction between city and country. LAB190 was initiated in 2013 as a pilot study. The initiative was taken by the Region and the others were invited to participate. A memorandum of understanding was signed by the political leadership at regional and local levels pointing out Food production, Tourism and Infrastructure as the important topics to focus on for the future collaboration. A crosssectoral action group and a cooperation agreement for the parties were formed.

In 2014, a survey was carried out on the three above mentioned topics. It was based on a bottom-up perspective and dialogue meetings with actors in the area and resulted in proposals for various development projects. The survey also included compilation of natural and cultural environments, restaurants, housing facilities and communications. In addition, a survey was sent to nearly 450 landowners in the area with focus on their activities to get a picture of the green enterprisers in the area. In early 2015, the action group presented a proposal for an Inter-municipal Development Plan15 with overall objectives and action plan for implementation from 2016 and onwards. The area should be a model for sustainable development. Concrete projects and actions based on the action plan have been started. The model emphasises the importance of coordination between business development, biodiversity, and social cohesion. The process is a way to try new methods of collaboration for societal challenges as well as for those of climate change and loss of biodiversity.

The process of LAB190 is a common concern for the development and management of the landscape. Relevant challenges they have identified:

- Very low prioritised area in the municipalities (seen as the backyard of the area).

- Many people (especially young) are far from the labour market

- Need to increase local influence in community planning

- Improve innovation power of the companies in the area

- Coordinate an increased cross-sectoral public sector

- Break the "feeling of backyard" and exclusion among mostly young people

One of the major challenges is to create interaction platforms between different sectors in the municipal structures and local development groups in the area (Stigson et al. 2009). We see the challenge of developing or restoring the cultural landscape, developing ecosystem services and work on 
nature-based solutions to drive long-term sustainable development in the area and in the region.

\section{KEY CONCEPTS}

\section{Climate impact}

The projected climatic changes in the region include extreme weather events in the form of intensive rainfall, strong winds and higher temperatures. The region is impacted by these weather events by flooded properties and financial losses to businesses around the river of Göta Älv and other watercourses. High winds affect, for example the forest sector, by storm fell trees causing large financial losses. A warmer climate means other insects and fungi, possibly creating damage for the agricultural and forest sector. A transition into more sustainable land use affects climate change in terms of both mitigation and adaptation. The city of Gothenburg discusses to implement major physical barriers for flooding control, which are relatively expensive adaptation measures. A change in forest management, can instead lead to a forest with increased adaptive capacity and increased climate resilience. This is accomplished through several potential adaptive benefits.

\section{Multifunctional sustainable land use}

A multi-functional sustainable land use can have a direct influence on the negative impact resulting from climatic changes by reducing risks of storm fell trees, since clear cuts, where such practices are implemented, increases the exposure of the trees adjacent to clear-cuts to strong winds. A multifunctional sustainable land use leads to a higher tree species diversity, which is more resilient to strong winds. A multifunctional sustainable land use also leads to a higher biodiversity, which decreases the damages caused, by insects and fungi in agriculture as well as forestry.

Agroforestry is recognized as a greenhouse gas mitigation strategy under the Kyoto Protocol Abbas et al. 2017). The mitigation potential of agroforestry is partly due to the greater potential of sequestering carbon compared to a single-species system because resources, such as nutrients, light and water, are taken care of more efficiently. However, we acknowledged that carbon sequestration in forests is complex and outside the scope of this project. Additionally, multifunctional land use can provide local produce from agriculture and forestry which currently is transported from longer distance and potentially produced in areas with less stringent climate policy and less focus on optimized and sustainable land-use. However, the possible change in emission from food production is complex since the main part of the emissions are created when households drive to the store to buy the food. While we acknowledge that agroforestry is not a silver-bullet neither for adaptation nor mitigation, the benefits for both areas have been proven in different contexts. We furthermore acknowledge that

\footnotetext{
${ }^{4}$ Stadslandet, Stadsbruk, LAB190
}

realizing these values require attention to these contexts from ecological, economic and social aspects.

Focus areas of the business model

Several ongoing initiatives in Gothenburg and its surroundings addressing sustainable land use by business development and network creation, has produced some interesting results. ${ }^{4} \mathrm{We}$ have summarised these into three focus areas as the basis for the proposed business plan on multifunctional sustainable peri-urban land use (Fig. 4).

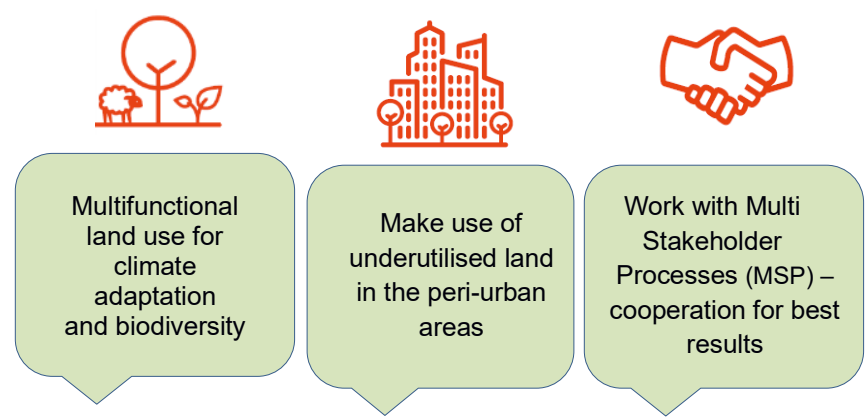

Figure 4. The three key focus areas. Source: authors' design

The First Focus Area is multifunctional sustainable land use. An agricultural system that integrates forestry, fruit-bearing trees and shrubs with farming and animal husbandry to create ecosystem services and environmental benefits, can create new values of land and provide benefits for sustainable landuse and resilience, such as local food and wooden products. It can also increase property value, improve aesthetics (in particular in road and industrial areas), psychological wellbeing and give recreational and educational opportunities as well as job creation (Delshammar, 2012). Forests also provide climate benefits including sequestering of gaseous air pollutants and particulates, carbon storage and energy conservation as well as pollination and storm-water attenuation. Other benefits are noise buffering and provision of wildlife habitat. As stated in the Introduction, multifunctional sustainable land use is closely related to agroforestry referring to "land-use systems in which trees are grown in combination with agriculture on the same land". Agroforestry is a term originally used for Mediterranean and tropical land use and is now becoming a more widely used term also in temperate and cool-temperate areas (Némethy \& Szemethy, 2019).

Our Second Focus Area is the value of integrating the periurban zone in urban planning. Similar to many other urban regions, there is a large potential to develop the land in close vicinity to the city as well as in the suburbs. Benefits of the peri-urban land are access to agriculture and forestland, closeness to market, work force and infrastructure. These can create new values of land and resilience, such as supply of e. g. biomass through new demand for sustainable and more climate neutral innovative energy, materials, and food products (Bliss, 2019). 
Our Third Focus Area is that the realisation of the abovementioned benefits requires a multifunctional stakeholder approach for cooperation between local governmental bodies, the academy, industries, civil society, and the local population. In general, individual stakeholders cannot drive this development on their own and we see a lack of cooperation between these actors when building a sustainable local economy. Multifunctional Stakeholder Process (MSP) is a way of bridging the gap when working with local processes for sustainable development. There is further a need to create a coordination platform that connects stakeholders, for example landowners with innovative entrepreneurs. Through cooperation, the potentials are much higher to develop new green businesses in peri-urban areas (McAfee, 2010).

\section{METHODOLOGY}

\section{Development of business models}

There has been an upsurge in interest for business models that allows companies and organisations to adopt and gain value from green economy, climate and resource efficient market developments (Maxwell, 2013). Following this, traditional tools to identify market and product positioning, lean production etc., has been complemented by new methodologies, such as business model canvases. This chapter explains the approach to how the business model was identified, the data collection methods applied, and a short introduction to the Value Proposition Canvas (VPC) and Business Model Canvas (BMC) utilized in this project.

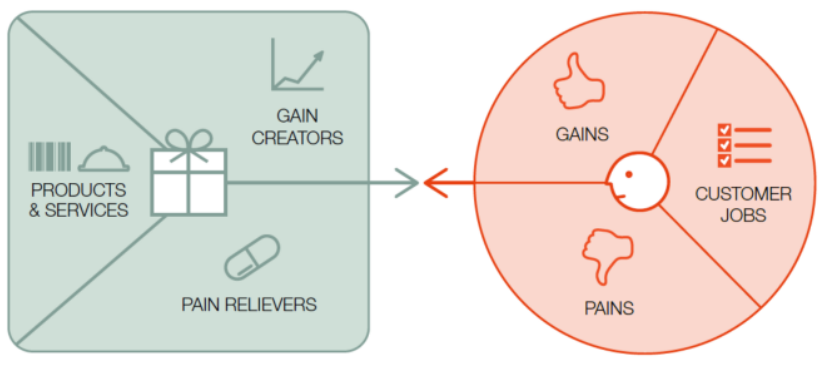

Figure 5. Value Proposition Canvas (VPC) (the baseline for the interviews as well as the Business Model Canvas).

A methodology based on the Strategyzer approach involving Business Model Canvas and Value Proposition Canvas was initially selected based on both the appropriateness for exploratory research into customer value as well as their lean approach to documentation and information sharing. Furthermore, the Business Model Canvas has now won acceptance as de facto standard in both industry and academia as an approach to connect customer values and business model design. The initial task was to identify stakeholders connected to the overall idea of facilitating a transformation towards a multi-functional sustainable land use in peri-urban areas. A workshop was held identifying existing business models and for each business case the value stream, i.e. who created the value for who. Stakeholders were identified and highlighted in each of the business cases. The stakeholders where then categorized into different groups that formed our primary stakeholders to be referred to for upcoming work. The primary stakeholders were identified as landowners, forest owners, region and city officials, ordinary citizens (with an interest in gardening/food production) and other associated work roles such as carpenters and city farmers. The interviews were carried out in the LAB190 area. All interviews and workshops were documented as separate meeting protocols.

The VPC (Fig. 5) was used as the template towards the interviews to initially observe and identify the current practice i.e. (customer jobs) that the identified stakeholder undertook. With the customer jobs as a basis we further identified the current barriers and problems (pains) within the organization. As potential ideas were discovered they could hence be presented as solutions to such pains. In parallel, the methodology calls for identifying current benefits the stakeholder identifies with the baseline practices, which makes it important for us to either enhance these gains, or make sure that they are not affected in a negative way as pains are removed. By the end of the study interviewees were identified to validate the selected business model. These validation approaches made sure to find evidence that the gain creators and pain relievers are likely to support the stakeholder. In order to present a complete BMC, the VPC was eventually expanded into complete BMC for one selected and a few supporting BMC. The advantage gained through expanding the VPC to a complete BMC was to get an overview of supporting processes and structures to ensure delivery of the service to the core stakeholders. The VPC is basically focusing on the customer values where the BMC also includes the practicalities of actually delivering and financing the venture. The main BMC was utilized by Strategyzer $(2015)^{5}$ as depicted in Table 1 .

\section{Validation of business models}

When performing a business model validation, in early stages, uncertainty is high. It is also a potential risk that the customer misunderstands what is tried to be conveyed in the business model, often stating an idea verbally may have the effect that the stakeholder finds the idea interesting and willing to try it. However, when the day comes, and you are ready to start the test, the stakeholder might not be willing to invest the time and effort needed, or realize that now when there is a distinct product or service, this is not what the stakeholder perceived. There are several means of getting around this problem. One way, applying the 'Lean Start-up Methodology' where several low-cost prototypes are tested, to mimic the real product or service at a very low cost of both time and resources. To start experimenting with the ideas in an early phase may help to see the difference of what the stakeholders say, what the stakeholders do, and what they are willing to pay or invest.

${ }^{5}$ https://www.strategyzer.com/canvas 
Table 1. The structure of Business Model Canvas (BMC)

\begin{tabular}{|c|c|c|c|c|c|}
\hline Key partners & Key activities & \multicolumn{2}{|c|}{ Value proposition } & $\begin{array}{c}\text { Customer } \\
\text { relationships }\end{array}$ & Customer segment \\
\hline $\begin{array}{c}\text { Landowners (public \& } \\
\text { private) } \\
\text { Possible organisations } \\
\text { or companies interested } \\
\text { in the role as a } \\
\text { facilitator if the City } \\
\text { does not take this role. } \\
\text { The Community /City }\end{array}$ & $\begin{array}{l}\text { Land leases for "city } \\
\text { farmers" and "wood } \\
\text { producers" include, } \\
\text { other than the actual } \\
\text { land, some basic infra- } \\
\text { structure, the activities } \\
\text { of the facilitator } \\
\text { assisting customers } \\
\text { with for example } \\
\text { market and agricultural } \\
\text { support. Set up an } \\
\text { incubator and } \\
\text { agroforestry centre. }\end{array}$ & \multirow{3}{*}{\multicolumn{2}{|c|}{$\begin{array}{l}\text { New regulations enable } \\
\text { municipalities to rent } \\
\text { out land for } \\
\text { commercial agriculture } \\
\text { to private persons. } \\
\text { Previously, the land } \\
\text { could only be used for } \\
\text { private food production } \\
\text { purposes when leasing } \\
\text { land in the form of } \\
\text { allotments etc. } \\
\text { Other than the rent of } \\
\text { the land, the } \\
\text { municipality provides a } \\
\text { facilitator, the } \\
\text { municipality itself or } \\
\text { another organisation. } \\
\text { The facilitation } \\
\text { includes market } \\
\text { channels, } \\
\text { communication, } \\
\text { agriculture support, } \\
\text { training, and business } \\
\text { development support } \\
\text { etc. The rent includes } \\
\text { fencing of the plot, } \\
\text { water for irrigation, } \\
\text { tools and tool storage } \\
\text { as well as other } \\
\text { facilities that can easily } \\
\text { be shared with other } \\
\text { customers. }\end{array}$}} & $\begin{array}{l}\text { The customer expects a } \\
\text { basic infrastructure, } \\
\text { other than the land, that } \\
\text { can be shared with } \\
\text { other customers. }\end{array}$ & $\begin{array}{l}\text { Customers, also called } \\
\text { city farmers and wood } \\
\text { producers, including } \\
\text { organisations, small } \\
\text { businesses, companies, } \\
\text { community groups etc. } \\
\text { with the aim of } \\
\text { commercial organic } \\
\text { food or wood } \\
\text { production in the city } \\
\text { and in the outskirts of } \\
\text { the city. Customers are } \\
\text { not those with the }\end{array}$ \\
\hline \multirow{2}{*}{$\begin{array}{l}\text { Wood sector producers } \\
\text { Others, such as fencing } \\
\text { companies }\end{array}$} & Key resources & & & Channels & $\begin{array}{l}\text { interest of large-scale } \\
\text { monocropping, but }\end{array}$ \\
\hline & $\begin{array}{l}\text { The municipality owns } \\
\text { public land, which } \\
\text { many times are part of } \\
\text { the land reserve for } \\
\text { future exploitation. } \\
\text { Private landowners } \\
\text { interested in the model } \\
\text { also have resources. } \\
\text { For basic infrastructure } \\
\text { it requires fencing } \\
\text { tools, water utilities, } \\
\text { sewage etc. which } \\
\text { simplifies the farming } \\
\text { for the customers, and } \\
\text { which are services to } \\
\text { be shared by several } \\
\text { customers. Central for } \\
\text { a successful business } \\
\text { development is also a } \\
\text { facilitator. }\end{array}$ & & & $\begin{array}{l}\text { People in the same } \\
\text { neighbourhood is one } \\
\text { important group to } \\
\text { reach as land leasing } \\
\text { can create a sense of } \\
\text { identity with several } \\
\text { advantages for the } \\
\text { municipality. } \\
\text { Awareness of service } \\
\text { through web and } \\
\text { advertisements }\end{array}$ & $\begin{array}{l}\text { rather customers with a } \\
\text { business model } \\
\text { designed for } \\
\text { multifunctionality of } \\
\text { the land. They have a } \\
\text { sustainable business } \\
\text { model and can deal } \\
\text { with e.g. unique } \\
\text { products } \\
\text { (super fresh, special } \\
\text { weeds etc.), processing } \\
\text { and marketing, area } \\
\text { development, surplus } \\
\text { resources, circular } \\
\text { economy, surplus heat, } \\
\text { recycling waste, shared } \\
\text { economy education, } \\
\text { events, study visits etc. }\end{array}$ \\
\hline \multicolumn{3}{|c|}{ Cost structure } & \multicolumn{3}{|c|}{ Revenue streams } \\
\hline \multicolumn{3}{|c|}{$\begin{array}{c}\text { The most important cost is that of the facilitator as well as the } \\
\text { basic infrastructure of fencing, water, tools, tool storage and } \\
\text { road network. The actual cost of the land is not always of } \\
\text { relevance since the land, if not leased, possibly remains } \\
\text { unused. }\end{array}$} & \multicolumn{3}{|c|}{$\begin{array}{l}\text { The revenue for the municipality includes the income from the } \\
\text { leases in financial terms. Other revenues could be job creation of } \\
\text { the companies or organisations leasing the land. Indirect benefits } \\
\text { are tax income and social support savings for the community. }\end{array}$} \\
\hline
\end{tabular}

As a Climate-KIC Accelerator project, with the aim to deliver a validated (early-stage validation) business model, the validation is made through interviews and workshops. Interviews and workshops were carried out to clarify whether or not the intent was to explore (gain more and new knowledge in a new field) or to validate (test the idea on a presumptive stakeholder). The validation interviews focused on getting the stakeholder on the same level as the project team (knowledge wise) and to get valuable feedback on the presented business model. This feedback was then used to either validate, indicate if this business model is good as it is, or if it needs further improvement.

For qualitative research projects, a model presented by Maxwell (2013) is often used. It recommends eight techniques that can be used for testing validity:
1. INTENSIVE, LONG-TERM INVOLVEMENT, which provides more robust data and opportunities to test hypotheses.

2. RICH DATA through e.g. comprehensive transcripts of interviews that cover different aspects of a situation.

3. RESPONDENT VALIDATION, i.e. letting subjects review the data and conclusions derived based on their responses.

4. INTERVENTION into the research setting to examine effects of proposed solutions.

5. SEARCHING FOR DISCONFIRMING EVIDENCE to avoid ignoring data that do not fit a theory.

6. TRIANGULATION by which information is collected using a variety of methods and sources to mitigate the risks of bias.

7. QUASI-STATISTICS whereby quantitative claims can be 
tested and data made more explicit.

8. COMPARISONS, e.g. using multiple case studies, which provide the opportunity to isolate variables in order to study causality.

In this project, we have had the opportunity to focus mainly on 3) Respondent validation and 6) Triangulation. For the long-term perspective (after a demonstrator project) especially validation method 1 and 2 will be further valid.

\section{BUSINESS MODEL FOR MULTIFUNCTIONAL SUSTAINABLE PERI-URBAN LAND USE}

\subsection{Results from interviews}

\section{Green businesses}

LAB190 carried out a larger study to map the green business resources in the LAB190 area. The work was carried out through around 140 questionnaires and a selection of qualitative interviews of selected businesses. The results show that there is a big focus on large agricultural monocultures with traditional products with low value. These do not seem to take benefit of being close to the urban markets. There is further a lack of sustainable business models or innovation in the agriculture sector. Detailed results are presented in the report Mapping of resources.

\section{City of Gothenburg}

Gothenburg is, through political support, nationally and internationally in the front when it comes to urban cultivation. The Property Management Department has had a prominent role in this work. Since 2011, they have, through its mission urban agriculture, developed a good method for meeting the demand for cultivation in the city and for inviting co-creation through public space cultivation. In addition, urban agriculture, within the framework of the Vinnova project Stadsbruk, has explored and developed methods and working methods to create conditions for commercial farmers in and around the city. Stadsbruk is a new way to grow in the city. The City of Gothenburg has a political mission to develop the agricultural land for ecological food production. They want to create opportunities for cultivation career, from allotments to hectare.

\section{Forest and wood chain}

The following section summarizes the interviews carried out with local actors and landowners. A major challenge with the local forest's potential is the quality and hence the difficulty of competing with wood from northern Sweden. Products that require lower quality, e.g. building materials or wood to cheap wood chains, has the greatest demand for local wood as well as new innovative ways of using the wood, such as cross laminated timber, textile etc. Exceptions are deciduous wood, but the challenge here is that there is such a small and specialized market that it does not give potential to any major business opportunities. However, it is good for biodiversity and to reduce storm damages.

Another challenge is the change in generation. Several local carpenters and sawmills still inherit the enterprise from their parents, while the next generation showed much less interest in taking over. It is also difficult for the existing carpenters to find competent staff. These risks seeing an extinct craftsmanship in the countryside. Below, the findings from the interviews are summarized. The findings are of course dependent of the persons selected for interviews. Another selection could possibly give different answers.

\section{Larger private forest owners}

Interviews show that the major landowners included in the study are primarily interested in economics as profitability is necessary for their businesses. Climate, ecological or social commitments are of less priority. They also argue for spruce as the most climate efficient method and they see few possibilities of forest gracing or other production than spruce on the woodland due to poor profitability.

Spruce is the most common tree in the area, and this is partly due to that spruce together with some pine is good for the thin soils according to the interviewees. The purpose is also to produce as much trees as possible and spruce is a good fastgrowing specie. Deciduous trees are less economical as there is no significant market for it. Selective forestry is not considered effective or profitable according to the forest owners. The forest owners interviewed are not positive to deciduous trees, nature 2000 and nature reserve. Pastures are not used as it is difficult to make meat production profitable. There are, however, meat producers in the area with good businesses. Unused pastures could be switched to another type of production, but it does not seem attractive to landowners. Timber is sold primarily to the big sawmills. Several forest owners are members of one of the big companies and therefore prioritize to sell to them even though they get a lower price. Price is otherwise, according to the landowners, the most important criteria for sales. The forest is, according to the interviewed, Sweden's single largest export product and accounts for $50 \%$ of all net exports. There is a growing demand for wood to the construction sector.

\section{Processing (carpentry and construction companies)}

Interviews with the processing sector show that the demand for local wood is very small. The wood from Northern Sweden comes from slow growing trees and has thus much higher quality than the fast-growing trees in the south. A major part of the northern wood is certified to be sustainable (often FSC-labelled). However, end-customers rarely ask for sustainable wood. Another obstacle is that the local timber owners cannot ensure enough quantities of the same quality wood. There are products where the local wood could be used, e.g. cuttings to ceilings. Small and medium-sized construction companies are dependent on delivering quality and often specialized solutions. They are often specialized in local demands on a relatively narrow market. It may be special assignments with the renovation of churches or other buildings with special conditions. Some have their own forests and contact with small sawmills to produce a range or a special product for individual renovations.

\section{Large construction stores}

The construction store chains have a centralized procurement department who are in charge of procurement of wood and wood products. The individual stores have no ability to 
choose wood products from small local sawmills or other local actors. Central agreements with major suppliers are crucial for keeping an attractive price level to the customer. Customers rarely demand Eco-labelling, but quality is often important even if price is an important competitive factor. Customer service is a very important part as well as the ability to meet new customer needs

\section{Small construction stores}

According to the small construction stores, the most important factor for purchasing wood is on time delivery of timber and wood. The quality of the wood is also very important to the customer, which are mostly local construction companies. In a small local market, building companies deliver quality to their customers. Quality encompasses both the workmanship and the wood. Ecolabelled wood is available through coordinated purchasing channels and agreements but are rarely demanded by the customer. However, an eco-labelled timber could attract a particular customer group.

\section{Municipal landowners}

Much of the Municipality's forest is located in urban areas and the highest value is considered to be the social benefits that the forest provides although a small profit is made from the timber sold. This means that there is a greater tendency for change and willingness among the Municipalities to meet the citizens' need for recreation, well-being and to attract visitors and tourists to the Swedish forests. There is also a much more pronounced interest in maintaining or increasing biodiversity, but it is pointed out that there are often complaints from local residents if you leave a lot of branches and dead wood in the forest. Many people think it looks like junk. This is rather an educational challenge to explain the importance of dead wood for the biodiversity to citizens (Lucas et al. 2008). Deadwoods, trunks and branches, in forest ecosystems contribute to increased biodiversity. Mature ecosystems also have a good ability to keep carbon dioxide. In Gothenburg, the situation is a bit different, as they own about $70 \%$ of all land (including forests). There are no resources for maintaining the forest. They are open to collaborations and new innovative test projects and are willing to provide forest for this.

\section{Small sawmills}

There are a number of small sawmills in the area, however, they are fewer than in the past and with the generation change, more and more are closing down. The profitability is often low but may be a complement to other income sources. In general, they are willing to develop their products to meet customers with specialized requirements such as building care measures in older churches or other cultural environment-intensive buildings. Ecolabelling is often not demanded by the customers. There is little cooperation between the other sawmills or other wood business actors. The products are typically sold in the immediate area, which means a radius of approximately 60 kilometres.

\subsection{Business Model Canvas}

After the interviews, one existing business model stood out as the most interesting for supporting multi-functional sustainable land use in peri-urban areas. This business model is called Stadsbruk. Stadsbruk is a project funded by the Swedish Innovation Agency, Vinnova. Four cities in Sweden have been part of the project: Gothenburg, Malmö, Kristianstad and Växjö. The aim of Stadsbruk is for cities to support new green businesses by leasing land for commercial green business development and provide business support with an incubator for training and basic infrastructure. The following text is to a large extent based on the project Stadsbruk summarized in Rasmusson et al (2016) and the interviews.

In this Accelerator project, some possible ways to develop Stadsbruk were identified. The first involves including periurban forestland for land lease. This implies several challenges as the forest lifetime could be more than 50 years compared to a couple of months for an annual crop. However, a large potential is identified because of the large areas of unmanaged forestland owned by the municipalities in the area as well as private landowners. Forestland can be used for selective forestry where the wood is developed locally for the local market. Research should be connected in the way that new innovative materials from wood can be tested and developed locally. Secondly, a possible way of developing Stadsbruk is to involve a larger diversity of enterprises where people are from all sectors of society and possibly also farmers and forest owners who have worked with land use their entire careers in contrast to the current model where most participants are in the beginning of their careers. In this way, green businesses could learn from urban agriculture in terms of initiatives for new market channels. Thirdly, we propose in this Accelerator project, to include the development of a physical, built centre in the LAB190 area as a meeting platform for stakeholder interaction, learning and training. One option is to locate a centre at the proposed Angered farm run by Agricultural school, however this has to be established and confirmed. This is similar to Botildenborg in Malmö.

Finally, it is of interest to investigate if it is possible to work even with private landowners. The business model has been created for any landowner, private or public, interested in leasing land to companies working with food and wood production. It has also been created for any partner interested in acting as a facilitator.

\section{Value proposition}

Selected questions for guidance:

- What is new with this proposition?

- What value do we deliver to the customers?

- Which one of our customer's problems are we helping to solve?

- Which customer needs are we satisfying?

Cities many times reserve land in the outskirts of the city for future exploitation and these land reserves can temporarily be 
used for food and wood production. New regulations enable municipalities to lease land for commercial agriculture to private persons. Previously, the land could only be used for private food production purposes when leasing land in the form of allotments. Other than the rent of the land, the municipality provides a facilitator, the municipality itself or another organisation. The facilitation includes market channels, communication, agriculture support, training and business development support etc. Experiences show that the facilitator role is central for the success of the companies. The companies many times have a lot of knowledge on the use of the agricultural productions, but less on how to actually sell the produce.

In the City of Gothenburg, the facilitator role is taken by the Department of Property Management. In other cities, such as Malmö, this role is taken by a company (Xenofilia AB). The rent includes fencing of the plot, water for irrigation, tools and tool storage as well as other facilities, such as toilets, that can easily be shared with other customers. This is main difference from other agricultural practices most often centred around a farm including all these facilities and basic infrastructure. The cities encouraging peri-urban sustainable land use align with several policy documents, such as the General Plan, the Blue Green Plan and the Inundation Plan as pointed out by the City of Malmö (Nilsson and Andersson 2017). The value to customers, companies leasing land, is land close to the city which enables the customers, if wanted, to live in an urban area and easily commute, for example with a bike, to the peri-urban farm. Furthermore, the business model provides customers with a network with other customers who possibly experience similar challenges.

\section{Customer segment}

Selected questions for guidance:

- For whom are we creating value?

- Who are our most important customers?

Customers are companies, organisations, and community groups etc. with the aim of commercial sustainable food or wood production in the peri-urban areas. Customers are not those with the interest of large-scale mono-cropping, but rather customers with a business model designed for multifunctionality of sustainable land use. They have a sustainable business model and can deal with unique products (super fresh, special weeds etc.), processing and marketing, place making area development, surplus resources, circular economy, surplus heat, recycling waste, shared economy education, events, study visits etc. Customers are neither the organisations focusing on producing food in the cities. We exclude these initiatives in this project as we find there are already many projects supporting these urban initiatives. Stadsbruk have concluded that it is crucial that these enterprises have a deep knowledge about what it implies for being a farmer in terms of for example the intensive labour needed in summertime during the main period of vacation. For these reasons, the companies interested in leasing land are screened according to certain criteria.

Key activities

Selected questions for guidance:
- What key activities do our value proposition require?

- What are our distribution channels?

- Customer relationships?

- Revenue streams?

Land leases for farmers and wood producers include, other than the actual land, some basic infrastructure, the activities of the facilitator assisting the customers with for example market and agricultural support. Set up an incubator and physical centre.

Key partners

Selected questions for guidance:

- Who are our key partners?

- Which key activities do partners perform?

- Which key resources are we acquiring from partners?

- Who are our key suppliers?

The key partners identified are the following:

- Landowners (public \& private)

- Possible organisations or companies interested in the role as a facilitator if the City does not take this role.

- The municipality

- City-farmers

- Wood sector producers

- Others, such as fencing companies

Customer relationship, key resources and channels Selected questions for guidance:

- What key resources do our value proposition require (physical, intellectual, human and financial)?

- Through which channels do our customer segments want land to be reached?

The municipality owns public, which many times are part of the land reserve for future exploitation. Private landowners interested in the model also have resources. For basic infrastructure it requires fencing tools, water utilities, sewage etc. which simplifies the farming for the customers, and which are services to be shared by several customers. Central for a successful business development is also a facilitator. People in the same neighbourhood is one important group to reach as land leasing can create a sense of identity with several advantages for the municipality. Awareness of service through web and advertisements.

Cost structure and revenue stream

Selected questions for guidance:

- What are the most important costs inherent in our business model?

- For what value are customers really willing to pay?

The most important cost is that of the facilitator as well as the basic infrastructure of fencing, water, tools, tool storage and road network. The actual cost of the land is not always of relevance since the land, if not leased, possibly remains unused. The revenue for the municipality includes the income from the leases in financial terms. Other revenues could be 
job creation of the companies or organisations leasing the land. Indirect benefits are tax income and social support savings for the community.

\section{VALIDATION OF THE BUSINESS MODEL}

The business model is validated in a participatory setting where Västarvet provides a proven collaboration platform and an effective process - LAB190 - in which large parts of the anchoring work is done in the constituent municipalities and private entrepreneurs. A key point for the validation is feedback from key stakeholders in the supply and value chains in terms of how new forest-based products fit ina technical, economic, and social perspective. This includes expectations of demand, lock-in in present investments, perceptions, preferences etc. The results will be used to refine the business model and developing a narrative to explain and incentivize its use.

LAB190 consists of a steering group of politicians and a coordination group of officials. The steering group's overall view was that there are good opportunities to work with the business model in the LAB190 area and provide the coordination group with continued support in the development of the business model. Furthermore, the coordination group sees great opportunities to transform the business model into practical implementation and, in the same way as the steering committee, considers that the model will be successful in the area. Apart from the evaluation and validation of our business model, several other, supporting business models have been described, assessed and validated since they represent those segments, which can be integrated into one holistic model.

\section{DESCRIPTION OF OTHER BUSINESS MODELS}

The following business models (BMs) that have been developed in the process inspire and support the Business Model for Multifunctional Sustainable Land Use in Periurban Areas. The seven BMs presented below can work as potential initiatives, of which some can be hosted inside the incubator. Each of them leads to the identified need to support business ideas regarding agroforestry and peri-urban land use to the market and build up a well-working business. Each BM is presented below in more detail under related heading and some of them are directly interconnected. For example, BM \#3 can support and increase the potential for success in BM $\# 1$. When people are interested in for example ordering locally sourced wood material, they can use the developed services and platform included in BM \#3.

\section{BM1 High-end sustainable villas}

This business model is typically directed towards companies selling, marketing, and producing high end private homes for upper middleclass individuals and families. They are becoming increasingly aware of their carbon footprint and are increasingly investing their resources in high quality products and services that offer a high social recognition. Typically, this buyer already owns an electric car, eats ecological food and wear organic cloths from the high-end brands. Core issues with the business model: Locally produced wood is ideal for being part either in loadbearing structures such as laminated or cross laminated beams and sections. Further, laminated wood is suitable for windows etc. which means that a large portion of the house may be built by locally sourced wood. The outer panels (the largest volume wood) may be sourced from locally harvested trees, without being factory processed and laminated, as it does not require prime quality wood. It is also possible to use panels in interior walls where it can replace chipboards, to offer increased sound. As such, this business model is possible to combine with BM3 for locally sourced "agroforestry wood".

Current house fabricators in the business have a high flexibility in their production, and some firms do not utilize prefabrication strategies at all which means that the flexibility to incorporate new and specific materials at the construction site is high. These companies are further used to their clients having very specific needs and whishes' (from having a 12car garage to a fully functional 8 people elevator).

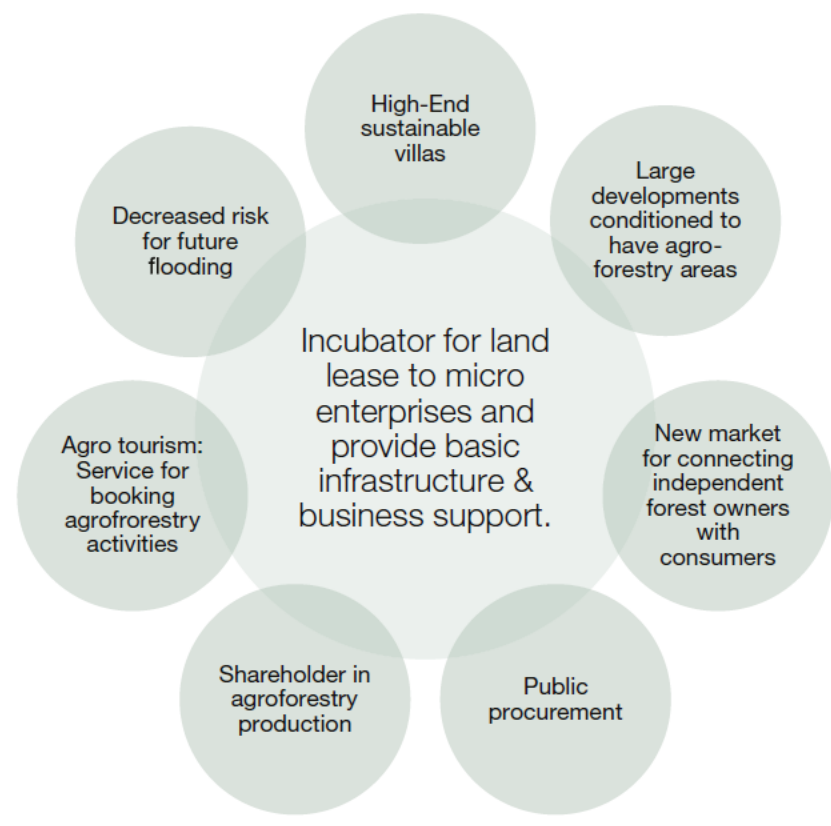

Figure 6. Representation of six business models that lead up to $\mathrm{BM}$ : incubator for land lease to micro enterprises and provide basic infrastructure \& business support. Source: authors' design

There are however issues with this business model. There is no evidence of that these customers would prefer a "lower quality" panel of locally sourced wood. There is no way to tell (on the outside) that this house panel is better compared to traditional panel. For example, high quality Siberian larch or other "high tech" and sustainable materials. For example, the Siberian larch does not need to be painted and is a wellknown material for this type of houses.

More details are available in the Business Model Canvas (BMC), suggesting e. g. collaboration with well-known 
architecture firms, integration of the latest "smart home" applications as e. g. tesla tiles (solar panels). Even though the current industry directed towards this business segment is flexible and would have no problems incorporating these changes, there is little evidence in that this will have a large impact on the housing market. To have large impact we must also target large developments and commercial building.

\section{BM2 Large developments conditioned to have agroforestry} areas

This business model targets primarily housing developers of large areas with (10-50) small houses. These developments are today required to fulfil several county restrictions and wishes concerning e. g. the construction of rental apartment, to green areas. This idea calls for both developers themselves as well as the counties to expand their knowledge on building viable projects where more attention is focused on the green areas. It would be possible to utilize the green areas better than they are today, and this will also most likely attract customers to buy these housing. As business model 9 talks about locally sourced wood for the houses, this business model promotes agroforestry areas where the people living in the peri-urban landscape may undertake agroforestry activates. It is also important to emphasize, that agroforestry may be established in many forms and can be regarded as a means for increasing, or rather restoring the previously lost biodiversity, increasing herewith the ecological resilience of the area (Nemethy and Szemethy 2019). Thus, agroforestry can enhance biodiversity and ecosystem service provision relative to conventional agriculture and forestry (Torralba et al. 2016) - depending on the development areas. As such the core of the business model does not lie in the actual value of the agroforestry products harvested from the green areas in the development but rather the increased economic value of the houses having direct access and benefit from these green areas. Further, this business model can be combined with
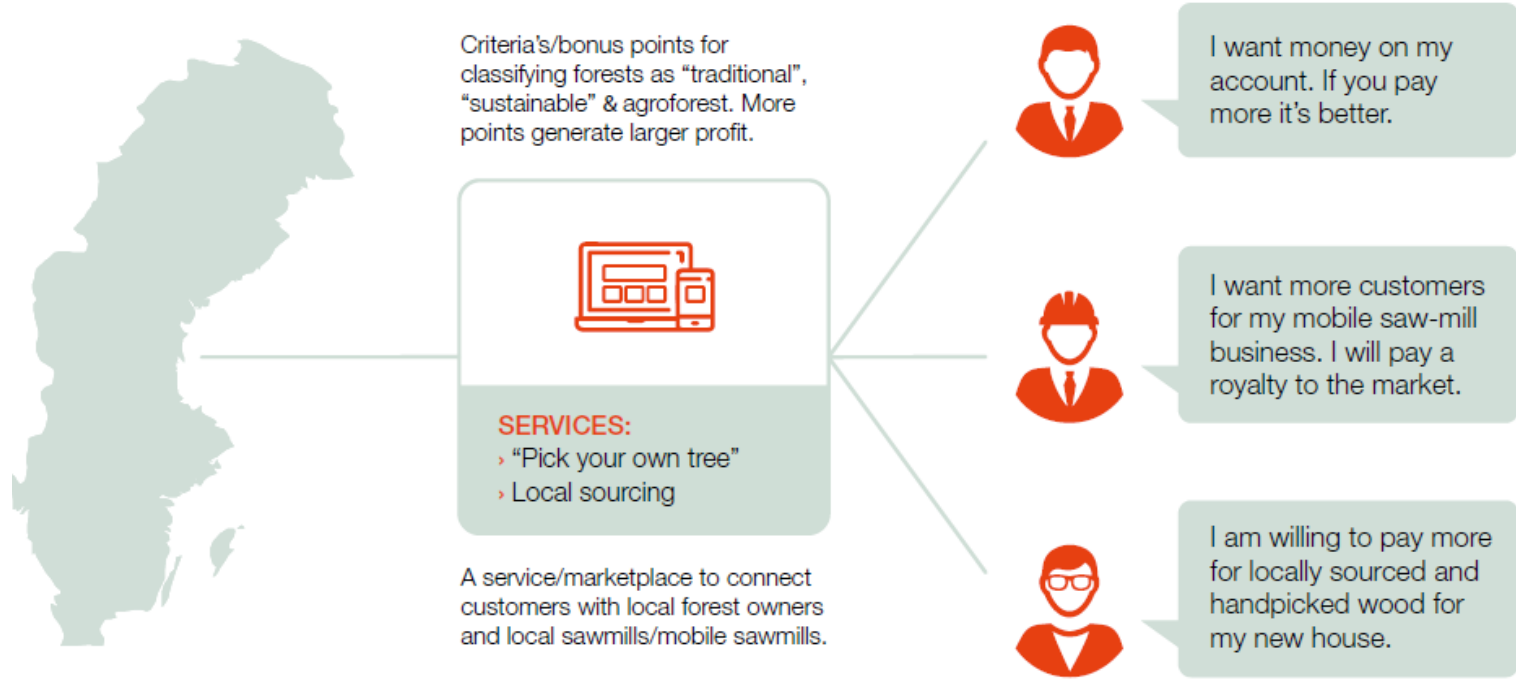

Figure 7. Forestry and agroforestry services: BM3 New market for connecting independent forest owners with consumers. Source: authors' design

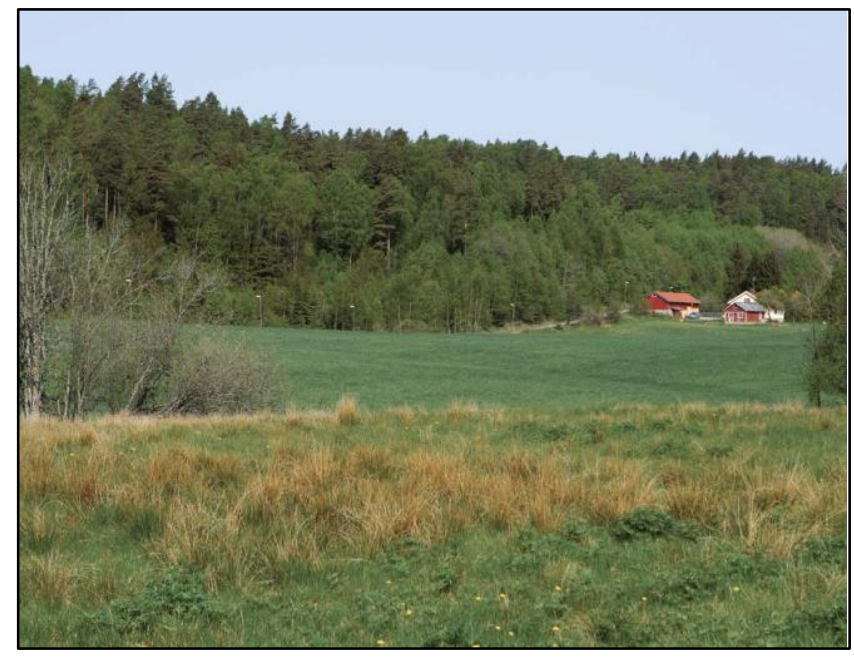

Figure 8. Typical common in a large development where the large areas are underutilised (Kungsbacka/Skanska). Photo: Anders M. Nilsson
BM4, if green areas are rented out for local citizens to "adopt a tree" or participate in maintaining the areas. The common will in that case have a (small) income from the green areas while at the time having (a potential) lower costs for maintenance. In the BMC we suggest consultancy services to consult both the original developers and the county to state better requirements on the green areas with insights in agroforestry applications and utilization (from optimal carbon dioxide binding, to growing vegetables, apples etc. locally), as well as the possibility to develop and sell agroforestry gardening services to the commons. To further promote this development, we further suggest in the BMC that the county takes responsibility for the initial maintenance of the green areas to assure their proper management, as well as this offers possibility for work and training for unemployed individuals. 
BM3 New market for connecting independent forest owners with consumers

The general idea with this business model is to enable a market where forest owners (specifically in the peri-urban area, close to the end user) is connected to the end customer using an online platform/marketplace where small and single person companies can provide logging and sawing services locally. Our initial investigations have shown that the forest owner must not be the driver of this business model as they are in most cases passive owners (Fig. 7). However, the end customer, who is actively searching for locally sourced wood, or even a specific type of tree, guarantees the active participation. The main value for the customer is the easiness way lower the final cost. The cost of the product will be highly dynamic depending on the supply and demand, transportation distance etc. that will be handled solely by the marketplace.

\section{BM4 Shareholder in agroforestry production}

This business model targets individuals who have land in the peri-urban (city) area that they either have high costs to maintain or have no obvious revenue from. This is typically County or city owned land, farmland close to cities and privately owned commons (owned by housing associations). Typically, these entities today pay external gardening companies to have the areas maintained, (typically having the
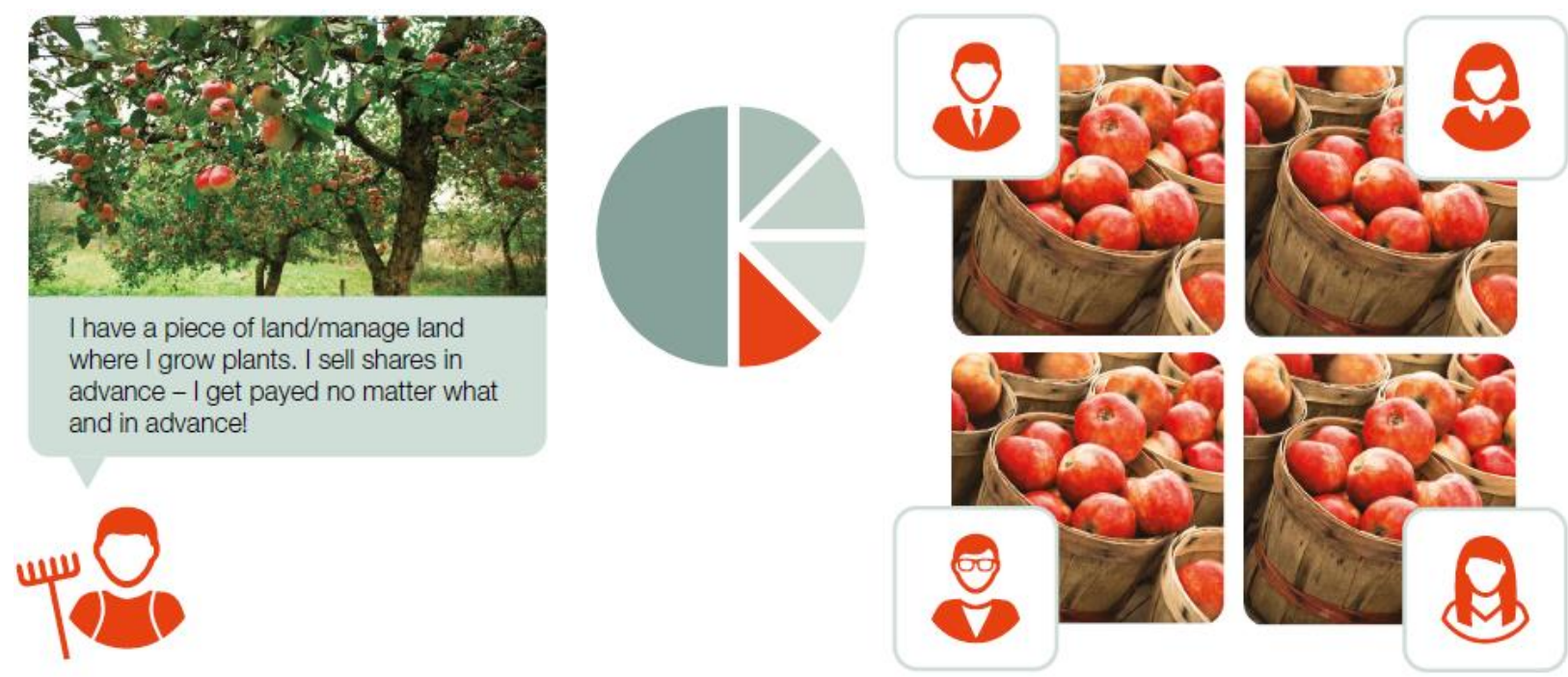

Figure 9. BM4 - shareholder in agroforestry production (fruit trees may be combined with in situ tree species). Source: authors' design

and accessibility to local wood through the marketplace and to be able to define preferences depending on the application need. The system will support the customer by providing proposed wood material that is recommended depending on the finalized products functionality and environment.

In today's situation it can be quite complicated to first learn about different wood alternatives and their specific characteristics in order to match that to once special need. With the new marketplace it will find the match between prerequisites set by customer on the final product with the proposed raw material alternative and further to the landowner and mobile sawmill. The overall system will help the landowner to reach potential customer that are interested in choosing peri-urban produced wood and in that way gain more interest for their grown products with limited added effort. The proposed marketplace will also increase the possibility for the sawmill owners to increase their network of customers and landowners in order to increase the use of their services.

In the BMC we also stress the possibility of decreasing the number of people involved for producing peri-urban high targeted wood material for specific customer needs and in that grass cut). With this business model (Fig. 9) we are offering the potential of a small income instead of a cost, when the land is either rented out as is with the purpose of growing e. g. vegetables or apples (Olsson \& Olsson, 2016). Some products such as apples seem to be less intrusive (as it does not compromise the use of the land as e. g. growing carrots would). However growing apple trees may invoke a start-up cost either financed by the original "shareholders" or by the association connected to the common. It could be further possible for public funding agencies to fund the initial cost (e. g. the plantation of 25 apple trees). This BM may be combined with BM2 but may also be introduced in existing commons (Fig. 8), they do not have to be new developments.

The landowner will organize the sales of the harvest either by a percentage of the whole harvest or by "adopting an apple tree" concept, where a shareholder is responsible and mentioning a specific specimen in the common. This could be applicable to commercial activities as indicated in the figure, as the "work needed" to maintain the area is probably low, however this is particularly useful in land that is not suitable for traditional agriculture and that may have very low return today. 
In the BMC we can see that the overall profitability of this $\mathrm{BM}$ is not substantial, but it may offer additional value to people living in the proximity to the common, and hence offer a service far simpler than renting a plot for gardening purposes. This BM is more suited towards "busy" people of today as the commitment towards the "adopted tree" may be flexible (Lucas et al. 2008). The BM further makes it possible to introduce gamification to promote "super gardeners" to participate in the harvest and maintenance of the common for added appreciation and possibly a larger cut when the harvest is divided.

\section{BM5 Public procurement}

A possible customer for agroforestry products, as ecological food and sustainable wood products, is the Municipality. They do, however, need to purchase according to the Law of Public Procurement, where there are strict requirements on even and high quality in large volumes and often processed products, such as processed food.

The City of Malmö has e. g. the requirement that producers must be able to deliver to all institutions governed by the Municipality which encompass thousands of delivery points.

These conditions make it difficult for local producers to deliver to the Municipalities. Smaller Municipalities could be more relevant for the local producers. In e. g. Växjö, they have chosen a model where the procured products are delivered to one distribution point. They also accept shared proposals so that several producers can deliver their products in the same purchase. This makes it possible for smaller producers to deliver and sell to the Municipality. The model further enables shared deliveries to that producers can take advantage of a sustainable logistics system leading to less emissions from trucks.
The abovementioned model and a new law in Sweden that makes it easier for municipalities to request social and environmental sustainability in the public procurement of products and services will open up the market for sustainable local producers. The public procurement Institution lists requirement and include e. g. engagement of long term unemployed in the company, organic food products, no chemicals or toxins in products. Products from local producers, both wood and food products, have high potential to meet these requirements. The model builds on a matchmaking between these products and public (as well as private) sustainable procurement.

Similar to new procurement law in Sweden, the EU has a proposal that encourage a new strategic approach to public procurement focusing on a number of priorities. These areas include greater use of innovative, green, and social criteria for public procurement; professionalisation of public purchasers and improved access for small and medium-sized enterprises. Potential customers are thus the Communities interested in sustainable procurement of local wood and food goods that respond to the requirements in terms of social, economic, and ecological sustainability.

This trend clearly contributes to the market potential (demand) for local products that can increase the profitability of local small to medium sized producers. This will further enable business development in the areas and job creation. For the communities, products (supply) will ensure sustainable and healthy products for the public institutions such as schools and hospitals.

Businesses that this model focus on i) processing actors in wood business: enterprises producing sustainable wood products for houses, interiors, etc. and, ii) eco-farmers who

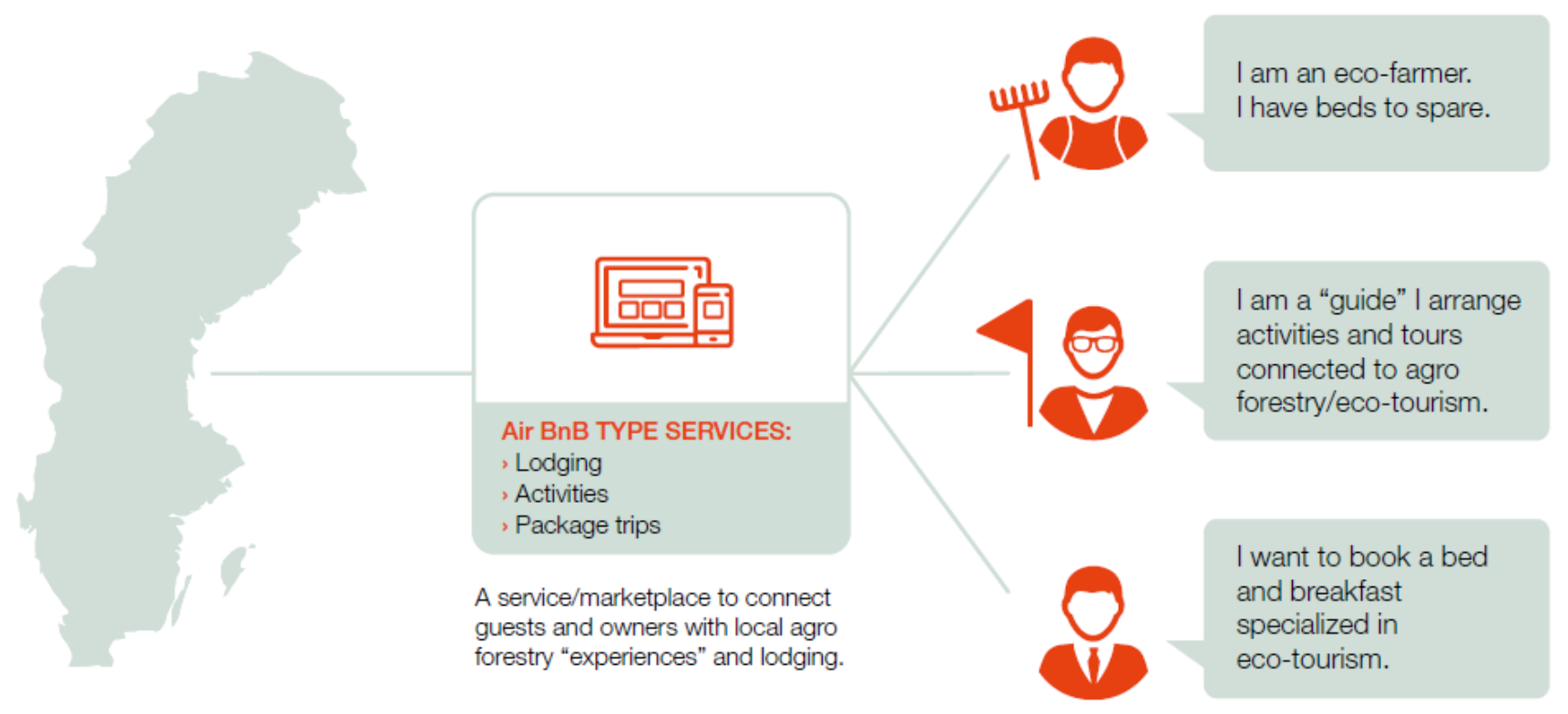

Figure 10. The Airbnb for agroforestry - lodging, activities, and package trips. Source: authors' design 
have beds to spare and are interested in improving the environment and willing to elaborate on new income sources. Strategic alliances between producers in each sector increase the potential to produce for larger procurements.

BM6 Agrotourism: service for booking agroforestry activities (the Airbnb for agroforestry)

This business model aims to take advantage of the often extra space in farmer/landowners houses as well as their land. Just as Airbnb takes advantage of people that are interested in new experiences and visiting new places to a relative cheap price. Agrotourism bring the possibility to the broad market to connect with farm-facilities to book overnight accommodations and other experiences facilitated by an experienced guide that arrange activities and tours (Fig. 10).

The business model brings new channels of income for the landowners that currently feel the pressure from the market. The model can also be developed further with other services such as selling locally produced products in an in-house marketplace, personal development in farming, the stress level in people today is increasing due to several reasons in their day-to-day life and a potential way to decrease this is to take a break from a hectic environment and explore what's outside the cities and participate in different experiences connected to farms and forests (Lindholm, 2013). Agrotourism is not scalable per say, however the platform can connect and build up a network of service suppliers. The basic channels of income are the hotel/hostel service as well as the guided experiences.

\section{BM7 Decreased risk for future flooding}

This business model builds upon the potential of decreasing the risk for future flooding. A strong input and driver for this business model is that according to the Directive 2007/60/EC of the European Parliament and of the Council of 23 October 2007 on the assessment and management of flood risks says: 1. Floods have the potential to cause fatalities, displacement of people and damage to the environment, to severely compromise economic development and to undermine the economic activities of the Community.

2. Floods are natural phenomena, which cannot be prevented. However, some human activities (such as increasing human settlements and economic assets in floodplains and the reduction of the natural water retention by land use) and climate change contribute to an increase in the likelihood and adverse impacts of flood events.

3. It is feasible and desirable to reduce the risk of adverse consequences, especially for human health and life, the environment, cultural heritage, economic activity, and infrastructure associated with floods. However, measures to reduce these risks should, as far as possible, be coordinated throughout a river basin if they are to be effective.

Catchment areas usually cover several municipalities. These municipalities have a planning monopoly in Sweden, which means that each municipality plans its territory without interference from other municipalities. Large impermeable surfaces, deforestation and drained areas cause water to stay short amount of time in the landscape. This causes problems when the effects of a municipality's planning affect other municipalities downstream a watercourse.

Increased future precipitation as a result of climate change give even higher flows with potential major negative social impacts. In order to avoid negative forecasted effects many municipalities have begun the work on technical solutions to reduce the damage caused by large flows in the waterways. These technical solutions are often costly and something municipalities themselves has to pay. Although the cause of the high flows is an unforeseen planning higher up in the water systems.

The evaporation decreases when forests are removed because much of the water remains in the trees and evaporates again. There are big differences depending on the season and how much precipitation is falling per time unit. Furthermore, the landscape's ability to retain water decreases if you harden surfaces or reduce wetlands. In Sweden, about $25 \%$ of wetlands have disappeared in the last century. In Europe, $60 \%$ of all wetlands disappeared before 1990 and almost another $5 \%$ over the 16 years thereafter.

There is currently emissions trading scheme for climate compensation but there is no system for purchasing water retention capacity from landowners in a water drainage area. Such a system could be tested and developed by building an organization where aquaculture can be marketed. Water retention can consist of letting the forest remain in place of its debris, thus retaining more water through increased evaporation and perspiration from the trees as they grow. One could also restore old wetlands and thus increase their ability to retain water high up in a water system. By retaining the water in the landscape, the flow decreases by a levelling. This becomes a way to work with nature-based solutions instead of expensive technical and sometimes dubious solutions.

The canvas model suggests a business model turning the landscape into a resource for landowners/municipalities in a new way. Instead of harvesting trees and dive out the woodland for increased tree production, the landowner can sell water holding services. The water balance equation describes the relationship between precipitation, runoff, storage, and evaporation. It is easy to understand why it's important to lower the runoff by increasing storage and evaporation for downstream benefits in reduced flooding. As said above floods are natural and cannot be prevented but we can reduce the damage by thinking and acting up streams. When harvesting forests, water evacuation is reduced to the atmosphere by reducing both transpiration and interception. This increases the runoff and reduces the water circulation time and increases the risk of floods. Hardened surfaces, of course, also provide a higher flow of water through the system while wetlands, lakes and ponds can provide storage. Furthermore, the conditions of water storage for water balance are continuously affected by the overall climate of the area near to watercourses and lakes. 
Water balance equation (Stella, 2019):

$$
\begin{aligned}
& \Delta \mathbf{S}=\mathbf{P}+\mathbf{I}-\mathbf{Q}-\mathbf{E T} \\
& \Delta \mathrm{S}=\text { Relative water storage }[\mathrm{mm}] \\
& \mathrm{I}=\text { Water supply }[\mathrm{mm}] \\
& \mathrm{P}=\text { Precipitation }[\mathrm{mm}] \\
& \text { ET = Evapotranspiration }[\mathrm{mm}]
\end{aligned}
$$

To be able to sell this "allowances" or rather water-holding services we need to create a system to connect potential landowners with customers and set the price that meet the demands from both sides. The connection could be by creating a website for landowners to market their land and for potential buyers to buy the service or to find the seller and work out an agreement.

\section{CONCLUSION AND WAYS FORWARD}

The City of Gothenburg has a leading role to support the development of sustainable urban farming in and around the city. Gothenburg is further the first city in Sweden that decided to practice selective forestry for their forests and to forbid clear-cut.

The Region Västra Götaland is further, through Västarvet, a driving force for developing a larger sustainable area. Although, agroforestry products are only contributing to the local economy at a very small scale, there is a big potential to enhance local economic and social development by integrating new ways of innovative business models.

The possibilities to develop the business model is perceived positive due to that the willingness is high among public and private stakeholders. It is further a model that is initiated and tested with good results.

\section{REFERENCES}

Abbas, F., Hammad, H,M, Fahad, S., Cerdà, A., Rizwan, M., Farhad, W., Ehsan, S., Bakhat, H.F. (2017): Agroforestry: a sustainable environmental practice for carbon sequestration under the climate change scenarios-a review. Environ Sci Pollut. Res Int. 2017 Apr;24(12):11177-11191. https://doi.org/10.1007/s11356-017-8687-0

Alfaro, M. Kanninen, M. Lobovikov, and J. Varjo editors (2010): Forests and Society - Responding to Global Drivers of Change. IUFRO World Series Volume 25. International Union of Forest Research Organizations (IUFRO), Vantaa, Finland.

Bliss, S. (2019). The Case for Studying Non-Market Food Systems. Sustainability, 11, 3224; https://doi.org/10.3390/su11113224

City of Gothenburg, (2017): Göteborgsbladet, http://statistik.goteborg.se/Statistik/Faktablad/Goteborgsblad et/

Council of Europe (2000): European Landscape Convention https://www.coe.int/en/web/landscape/home
Delshammar, T., (2012): Urban cultivation in Sweden (Stadsodling i Sverige); In: Delshammar et.al (2012): Stadsodling - Reflektioner och perspektiv från SLU Alnarp, Rapportserie Landskap Trädgård Jordbruk. In Swedish. Rapport 2012:31; ISSN 1654-5427; ISBN 978-91-87117-30-5 https://pub.epsilon.slu.se/10061/7/delshammar_et_al_13032 $\underline{\text { 8.pdf }}$

EEA (2006), Urban Sprawl in Europe - the ignored challenge. European Environment Agency, Copenhagen 10/2006. ISSN 1725-9177

Ekoweb (2016): Organic food market, market report 2016 (In Swedish: Ekologisk livsmedelsmarknad, marknadsrapport 2016). http://www.ekoweb.nu/attachments/67/45.pdf

Eriksson, L., Christer Björkman, C. \& Klapvijk, M.J. (2017): General Public Acceptance of Forest Risk Management Strategies in Sweden: Comparing Three Approaches to Acceptability. Environment and Behavior, Vol. 50(2) 159186; https://doi.org/10.1177/0013916517691325

European Commission (2016): Agroforestry delivers more ecosystem services than conventional land uses. Science for Environmental Policy, 28 October 2016 Issue 475.

FAO (2017): The future of food and agriculture - Trends and challenges. Rome. http://www.fao.org/3/a-i6583e.pdf .

FAO (1997): Urban and peri-urban agriculture www.fao.org/unfao/bodies/COag/cOAG15/docs/X0076E.DOC

Hunter, M.C., R.G. Smith, M.E. Schipanski, L.W. Atwood, and D.A. Mortensen (2017): Agriculture in 2050: Recalibrating Targets for Sustainable Intensification. BioScience 67(4): 386-391. https://doi.org/10.1093/biosci/bix010

Lindahl, K. B., Sténs, A., Sandström, C., Johansson, J., Lidskog, R., Ranius, T. and Roberge, J-M. (2015): The Swedish forestry model: More of everything? Forest Policy and Economics 77.

https://doi.org/10.1016/j.forpol.2015.10.012

Lindholm, A. (2013): Urban cultivation in urban planning and its contribution to social sustainability. Degree project in regional planning, Advanced level. In Swedish. Stadsodlingen i stadsplaneringen - och dess bidrag till samhällelig hållbarhet. Examensarbete inom regional planering, Avancerad nivå, 30 p, Kungliga Tenkniska Högskolan (KTH), Stockholm. SoM EX 2013-34

Lucas, K., Brooks, M., Darnton, A., Jones, J.E. (2008): Promoting pro-environmental behaviour: existing evidence and policy implications. Environmental Science \& Policy 11: 456-466. https://doi.org/10.1016/j.envsci.2008.03.001

Maxwell, J.A. (2013): Qualitative Research Design: An Interactive Approach. h (2nd ed.). Thousand Oaks, CA: Sage. ISBN-13: 978-1412981194; ISBN-10: 9781412981194 
McAfee, B.J.; de Camino, R.; Burton, P.J.; Eddy, B.; Fähser, L.; Messier, C.; Reed, M.G.; Spies, T.; Vides, R.; Baker, C.; Barriga, M.; Campos, J.; Corrales, O.; Espinoza, L.; Gibson, S.; Glatthorn, J.; Martineau-Delisle, C.; Prins, C.; Rose, N.A. (2010), Managing Forested Landscapes for Socio-Ecological Resilience, pp 399-440 Chapter 22 in G. Mery, P. Katila, G. Galloway, R.I.

Melander, D. (2013) Food producers are developing local collaboration linked to tourism and the hospitality industry (Livsmedelsproducenter utvecklar lokal samverkan kopplat till turism och besöksnäring), Stadslandet, Business Region Gothenburg. Utveckling Nordosts rapport 2013. In Swedish. www.utvecklingnordost.se

Némethy, S; \& Szemethy, L. (2019): The sustainability of woody biomass feedstock production and landscape management: land use, phytoremediation, biodiversity, and wildlife habitats ECOCYCLES 5:1 pp. 44-55., 12 p. https://doi.org/10.19040/ecocycles.v5i1.141

Nilsson, K., Pauleit, S., Bell, S., Aalbers, C., Nielsen, S. (editors, 2012): Peri-urban futures: Scenarios for land use change in Europe. Springer, ISBN 978-3-642-30529-0

Olsson, G.A. \& and Olsson, M. (2016): Matproduktion och urban hållbarhet, Mistra urban futures 2016:2. https://www.mistraurbanfutures.org/sites/mistraurbanfutures .org/files/almered-olsson-report-2016-2.pdf

Piorr, A., Ravetz, J., Tosics, I. 2011. Peri-urbanisation in Europe: Towards European Policies to Sustain Urban Rural Futures. A Synthesis Report. Academic Books,
Frederiksberg: Forest \& Landscape, University of Copenhagen, 2011. ISBN 978-87-7903-534-8 (paper) ISBN 978-87-7903-535-5 (electronic version)

Rasmusson A., Andersson G. and H. Nilsson (2016), Stadsbruk: en guide för kommersiell odling i staden. https://www.slu.se/globalassets/ew/org/inst/lapf/stadsbruk/st adsbruk.pdf

Statens Jordbruksverk (2017): Use of agricultural land 2017 Final statistics In Swedish: Jordbruksmarkens användning 2017), JO 10 SM 1703 - ISSN 1654-4102

Stella, J. M. (2019): Mathematical methodology to calculate the rate of water storage. International Journal of Hydrology, Volume 3 Issue 1, pp. $11-16$. https://doi.org/10.15406/ijh.2019.03.00156

Stigson, P., Dotzauer, E., Yan, J. (2009): Voluntary agreements as a vehicle for policy learning. International Journal of Global Warming 2:97-117. https://doi.org/10.1260/095830503322663393

Torralba, M., Fagerholm, N., Burgess, P., Moreno, G. \& Plieninger, T. (2016): Do European agroforestry systems enhance biodiversity and ecosystem services? A metaanalysis. Agriculture, Ecosystems \& Environment, 230: 150-161. https://doi.org/10.1016/j.agee.2016.06.002

Watson R. T., Noble I. R., Bolin B., Ravindranath, Verardo D. and Dokken D. (Eds. 2000): Land-use, Land-use change and forestry. Cambridge University Press, UK. pp 375. https://www.ipcc.ch/report/land-use-land-use-change-andforestry/.

(C) 2020 by the author(s). This article is an open access article distributed under the terms and conditions of the Creative Commons Attribution (CC BY) license (http://creativecommons.org/licenses/by/4.0/). 